\title{
Evaluation of acute dermal irritation and wound contraction by Gymnema Sylvestre and Datura Metel extracts in rats
}

\author{
Omale James, Ajidahun Bidemi Sunday \\ Department of Biochemistry, Kogi State University, Anyigba, Nigeria \\ Email address: \\ james.omale123@yahoo.com (O. James)
}

To cite this article:

Omale James, Ajidahun Bidemi Sunday. Evaluation of Acute Dermal Irritation and Wound Contraction by Gymnema Sylvestre and Datura Metel Extracts in Rats. American Journal of Biomedical and Life Sciences. Vol. 2, No. 4, 2014, pp. 83-88.

doi: 10.11648 j.ajbls.20140204.14

\begin{abstract}
In this study, to comparatively evaluate whether aqueous extracts of G. sylvestre and D. metel induce acute dermal irritation and or contract wound tests were performed using experimental animals. The skin of the rats was treated with these extracts $(0.5 \mathrm{~g} /$ dose $)$ and whether the animals sustained skin damage was determined by visual observation. The data demonstrated that the aqueous extracts of both plants did not induce acute skin irritation (toxicity) on the skin of the animals as assessed by pathological observations. Wound healing properties were evaluated using excision wound model. The groups of rats were experimentally wounded at the posterior neck area. An area of uniform wound of $7 \times 7 \mathrm{~mm}$ using millimetre rule was exercised from the dorsal back of the rats. The animal groups were topically treated with $G$. sylvestre and D. metel gels. Wound dressed with leaf, stem and flower of G. sylvestre and leaf, stem and fruit of D. metel gel significantly heal earlier than those treated with paraffin base, while the leaf and stem of $G$. sylvestre and leaf and fruit of $D$. metel healed wound better than povidone iodine. The results from the present study suggest that these aqueous extracts of $G$. sylvestre and $D$. metel have promising potential uses as cosmetic ingredients that do not induce significant levels of dermal irritation and exhibit wound healing properties. Wound contraction elicited by these plant parts in this investigation following topical administration strongly corroborates the verbal claims on their efficacy for these activities.
\end{abstract}

Keywords: Gymnema Sylvestre, Datura Metel, Wound Contraction, Dermal Irritation, Rats

\section{Introduction}

Investigations on the traditional use of medicine are recognized as a way to learn about potential future medicines (Fabricant and Farnsworth, 2001). It is well known that many medicinal plants are beneficial sources of minerals, vitamins, dietary fibre and various phytochemicals (Sarker and Nahar, 2004). Certain herbs are popular at present since their ingredients may not only regulate body homeostasis but also prevent several degenerative diseases (Panetal, 2008; Pan et al., 2009).

Plants have an immense potential for the management and treatment of wounds. A large number of plants have been used by tribal and folklore; in many countries for the treatment of wounds and burns. The presence of various health sustaining constituents in plants has attracted scientists to examine these plants with a view to determine potential wound healing properties (Nayak and Pinto-
Pereira, 2006). The medicinal value of these plants lies in their bioactive phytochemical constituents that produce definite physiological actions on human body (Akinmoladun et al., 2007). These constituents include various members of chemical families like alkaloids, essential oils, flavonoids, tannins, terpenoids, saponins, and phenolic compounds (Edeoga et al., 2005).

In cosmetic industry, evaluation of irritancy potential to human skin of any chemical or formulation is a necessity. This must be done by means of invivo and invitro tests to determine the risk of irritation due to the contact between these compounds and human skin. The most commonly used test is the rabbit skin irritation test described in the OECD test guideline 404 and in the European chemicals Bureau Annex V. part B.4 http://ecb.jrc.it/testing-methods/) which was initially described by Draize et al., 1994. In this 
animal test, the test substances, either raw material or finished formulated products, are to be applied on the rabbit's shaved skin. A score of skin reactions is based on physiological observations on the animals.

Plant extracts with pungent scents appear to cause skin irritation. Unwanted reactions to cosmetics are common in patients with allergic dermatitis (Nigam, 2009). Since various side effects may be caused by acute or chronic toxicity, irritation or sensitization, various invivo animal models, as well as invitro, semi invivo and ex vivo models, should be used in further toxicity studies, although they are modified tests (Draize et al., 1994). If a cosmetic component or constituent is demonstrated to be non-toxic to the skin in animals or clinical trials, its use should be approved. Although, cosmetic ingredients have rarely caused serious damage, no studies have conclusively demonstrated that these substances actively protect the skin or promote tissue regeneration as at this time.

According to traditional medicine practitioners, parts of Gymnema sylvestre plant such as leaf, stem, root and flower are used for medicinal preparation in form of decoction or concoction. The plant is claimed to have anti-diabetic effects in animal models (Sugihara et al., 2000). Historically, the leaves of Gymnema sylvestre were used for the treatment of stomach ailments, constipation water retention, and liver diseases. The plant can also be used in the management of snake bites, asthma, eye complaints, chronic cough, difficulty in respiration, colic pain, dyspepsia, and haemorrhoid etc. However, these claims are not supported by scientific studies. (Shanmugasundaram et al., 1981).

Traditionally, Datura metel is one of the 50 fundamental herbs used as Chinese medicine. Ingestion of Datura metel in any form is dangerous and should be handled with care. The most common medicinal uses of Datura metel are for skin conditions, anxiety, and respiratory ailments. The seeds are used as a substitute for opium (Ratsch, 1998). These activities could play some role in its effects on tissue repair. Therefore, the aim of the present study was to evaluate activity of Gymnema sylvestre and Datura metel extracts on excision wound models that would influence management of wound and also in order to assure safety of gel ointments from these plants, we conducted skin irritation tests on rat's skin in this present study.

\section{Materials and Methods}

\subsection{Collection of Plant Materials}

Gymnema sylvestre was collected from Ajaokuta Local Government Area, Kogi State, Nigeria during rainy season when the plant thrives well. Samples of the plant were rinsed properly in clean water to remove dirt. They were air-dried at room temperature for a period of three weeks and pulverized into powder using a mechanical hand blender and sieved. Datura metel was obtained from Kabba-bunu Local Government Area at No. 34 Fehinti-
Oluwa, Kabba, Kogi State, Nigeria and treated as above.

\subsection{Preparation of Plant Extracts}

The cold extract method was used in this extraction. $198 \mathrm{~g}$ of the powdered leaf, $271 \mathrm{~g}$ and $104 \mathrm{~g}$ of stem and flower respectively were weighed out on a weighing balance (metildo). $2000 \mathrm{ml}$ of distilled water measured out in a measuring cylinder and added to each of the powdered substances in plastic containers and left for a period of 5 days. The mixtures were filtered using a vacuum pressure pump (Edwards) and filtrates were concentrated at a temperature of $72^{\circ} \mathrm{C}$ to dryness using a uniscope laboratory water bath. This procedure was repeated for the parts of Datura metel used.

\subsection{Rats Skin Irritation Study}

An evaluation was conducted using four rats per group of four. Animals were anaesthetized with ketamine hydrochloride injection $(0.2 \mathrm{ml})$, this was done to prevent any movement of animals for at least two hours after administration following the guidelines of Organization for Economic Co-operation and Development (OECD) test guidelines 404: acute dermal irritation and (corrosion). The back of the animals was shaved free of fur with an electric clipper 24 hours before application of the sample. This was carefully done to avoid skin injury which could alter its permeability. Methylated spirit was then applied as an antiseptic to the shaved region with the aid of a cotton wool to prevent infections caused by bacteria. A millimetre rule was used to measure an area of $40 \mathrm{~mm} \times 30 \mathrm{~mm}$ on the shaved skin. For each group of rats, $0.5 \mathrm{~g}$ of aqueous extracts of the leaf, stem and flower of Gymnema sylvestre and distilled water $(0.5 \mathrm{ml})$ (control group) was topically applied on a free surface of the skin. This was repeated for the parts of Datura metel. The plant extracts were held in contact with the skin using a zinc oxide adhesive plaster and a non-occlusive bandage dressing for $24 \mathrm{hrs}$, after which the bandage and the test materials were removed and the surface of the skin was rinsed with distilled water and 1 $\mathrm{hr}$ later the sites were examined for skin irritation. Observation of the sites was done at $24 \mathrm{hrs}$ after application, and repeated at 48 and $72 \mathrm{hrs}, 7$ days and 14 days thereafter Scores corresponding to the skin reactions were attributed according to the scoring systems described by Draize and Spine (OECD, 2002).

\subsection{Ointment Preparation for Topical Application}

Gymnema Sylvestre leaf, stem and flower paste and Datura leaf, stem and fruit paste were used for the preparation of the ointment for topical application (Yagi et al., 1998). A $50 \%(\mathrm{w} / \mathrm{w})$ of extract ointments were formulated using soft white paraffin base (Cooper, 1987).

\subsection{Excision Wound Model}

Animals were anaesthetized with $0.2 \mathrm{ml}$ ketamine hydrochloride, this prevent any movement of the animals at 
least for two hours after the administration of the anaesthesia and left without being restrained (Rasheed et al., 2003).

The furs of the animals were removed by shaving dorsal back of the rat using electric clipper, then methylated spirit was applied to the shaved portion as antiseptic before wound creation (Morton and Melone, 1972). An excision wound of $7 \times 7 \mathrm{~mm}$ was made by removing full thick pieces of skin using sterilized surgical blade from a predetermined shaved area on the back of each animal. The experimental groups were topically applied with the extracts twice daily for consecutive 16 days. The group treated with povidone iodine drug and paraffin base served as reference standard and control respectively. A progressive decrease in the wound area was monitored periodically at every $4^{\text {th }}$ day interval. The wound contractions were measured by a tracing paper on the wounded margin and calculated as percentage reduction in wound area. The actual value was converted into percentage value taking the size of the wound at the time of wounding as $100 \%$. The animals were divided into five groups of four rats each. Group 1-5 were treated with paraffin base, povidone iodine, leaf, stem and

flower extracts of G. sylvestre respectively. This procedure was repeated for Datura metel plant parts used.

Measurement of wound closure was done on $8^{\text {th }}, 12^{\text {th }}$ and $16^{\text {th }}$ days.

\subsection{Experimental Animals}

The animals used for this experiment were albino rats of average weights between 180.65 to $235 \mathrm{~g}$ of both sexes. They were obtained from the breeder in Kogi State University Staff Quarter. The animals were housed in standard environmental conditions. Rats were fed with standard rodent diet and given water ad libitum. The study on the animals was carried out following the guidelines of the principles of laboratory animal care (WHO, 1985).

\subsection{Statistical Analysis}

All data were expressed as mean \pm S.E.M. and Graph Pad Instat (Data set 1.1SD) was applied to determine the significance of difference at $\mathrm{p}<0.05$.

\section{Results}

Table 1. Effects of Aqueous Datura Metel Leaf, Stem and Fruit Extracts on the Skin of Rats

\begin{tabular}{|c|c|c|c|c|c|c|c|}
\hline \multirow{2}{*}{$\mathbf{S} / \mathbf{N}$} & \multirow{2}{*}{ Group/Treatment $(0.5 \mathrm{~g})$} & \multicolumn{6}{|c|}{ Duration of Observation/Symptoms of Toxicity } \\
\hline & & $1 \mathrm{~h}$ & 24 hrs & 48 hrs & 72 hrs & 7 days & 14 days \\
\hline 1 & Control group Distilled water $(0.5 \mathrm{ml})$ & - & - & - & - & - & - \\
\hline 2 & Leaf & - & - & - & - & - & - \\
\hline 3 & Stem & - & - & - & - & - & - \\
\hline 4 & Fruit & - & - & - & - & - & - \\
\hline
\end{tabular}

- = no irritation observed

$+=$ irritation observed

Table 1 shows that there is no sign of dermal toxicity as no redness, erythema, oedema or eschar of any kind was observed. The experimental samples did not cause moderate or severe toxicity even after 14 days of observation.

Table 2. Effects of Aqueous Leaf, Stem and Flower Extracts of Gymnema sylvestre on the Skin of Rats

\begin{tabular}{|c|c|c|c|c|c|c|c|}
\hline \multirow{2}{*}{$\mathbf{S} / \mathbf{N}$} & \multirow{2}{*}{ Group/Treatment $(0.5 \mathrm{~g})$} & \multicolumn{6}{|c|}{ Duration of Observation/Symptoms of Toxicity } \\
\hline & & $1 \mathrm{~h}$ & 24 hrs & 48 hrs & 72 hrs & 7 days & 14 days \\
\hline 1 & Control $(0.5 \mathrm{ml}$ distilled water $)$ & - & - & - & - & - & - \\
\hline 2 & Leaf & - & - & - & - & - & - \\
\hline 3 & Stem & - & - & - & - & - & - \\
\hline 4 & Flower & - & - & - & - & - & - \\
\hline
\end{tabular}

- = no irritation observed

$+=$ irritation observed

The result on Table 2 indicates that there was no toxicity observed on the skin of the rats after topical application of the extracts

Table 3. Effects of Aqueous Datura metel Leaf, Stem and Fruit Extracts on Wound Contraction

\begin{tabular}{|c|c|c|c|c|}
\hline \multirow{2}{*}{$\mathbf{S} / \mathbf{N}$} & \multirow{2}{*}{ Group/Treatment } & \multicolumn{3}{|c|}{ Percentage Wound Contraction After Days } \\
\hline & & 8 & 12 & 16 \\
\hline 1 & Wound control (Paraffin base) & $21.08 \pm 7.83^{*}$ & $57.05 \pm 0.06^{* * *}$ & $90.00 \pm 1.62^{* * *}$ \\
\hline 2 & Standard (Povidone iodine) & $35.20 \pm 7.97^{*}$ & $85.05 \pm 0.06^{* * *}$ & $93.6 \pm 0.81^{* * *}$ \\
\hline 3 & Leaf gel & $50.15 \pm 8.37^{*}$ & $85.65 \pm 0.16^{* * *}$ & $99.30 \pm 0.81^{* * *}$ \\
\hline 4 & Stem gel & $41.25 \pm 0.17^{*}$ & $49.65 \pm 7.79^{* * *}$ & $71.25 \pm 0.17^{* * *}$ \\
\hline 5 & Fruit gel & $35.40 \pm 7.79^{*}$ & $63.90 \pm 7.85^{* * *}$ & $94.8 \pm 0.58^{* * *}$ \\
\hline
\end{tabular}


Results are expressed as Mean \pm S.E.M., $\mathrm{n}=4$. Mean values with the superscript $\left(^{*}\right)$ in the column are not significantly different from each other $(\mathrm{p}>0.05)$ when compared with standard and control. The mean with triple $\left({ }^{* * *}\right)$ in the same row are significantly different from each other $(\mathrm{p}<0.05)$ when compared with standard and control.

As presented in Table 3, wound contraction or closure progressed in days. The Leaf gel of D. metel had a better wound healing activity with $99.30 \pm 0.81 \%$ wound contraction in day 16 even better than the reference drug (Povidone iodine).

Results are expressed as Mean \pm S.E.M., $\mathrm{n}=4$. The mean values with the superscript $\left(^{*}\right)$ in the column are not significantly different from each other $(p>0.05)$ when compared with standard and control. The mean with triple $\left({ }^{* * *}\right)$ in the same row are significantly different from each other $(\mathrm{p}<0.05)$ when compared with standard and control.

The result of the effects of aqueous G. sylvestre leaf, stem and flower extracts on wound closure is as presented in Table 4. This result indicates that the leaf get is a better wound healing agent. Wound contraction progressed rapidly from day 8 to 16 with the topical application of the extract gels and the contractions were comparable with the reference standard used.

Table 4. Effects of Aqueous G. sylvestre Leaf, Stem and Flower Extracts on Wound Contraction

\begin{tabular}{lllll}
\hline \multirow{2}{*}{ S/N } & \multirow{2}{*}{ Group/Treatment } & \multicolumn{3}{l}{ Percentage Wound Contraction After Days } \\
\cline { 3 - 5 } & $\mathbf{8}$ & $\mathbf{1 2}$ & $\mathbf{1 6}$ \\
\hline 1 & Wound control (Paraffin base) & $21.08 \pm 7.83^{*}$ & $57.05 \pm 0.06^{* * *}$ & $90.00 \pm 1.62^{* * * *}$ \\
2 & Standard (Povidone iodine) & $35.20 \pm 7.97^{*}$ & $85.05 \pm 0.06^{* * *}$ & $93.60 \pm 0.81^{* * *}$ \\
3 & Leaf gel & $42.35 \pm 0.06^{*}$ & $85.50 \pm 0.17^{* * *}$ & $96.40 \pm 0.81^{* * *}$ \\
4 & Stem gel & $28.50 \pm 8.26^{*}$ & $64.25 \pm 8.26^{* * *}$ & $89.30 \pm 0.81^{* * *}$ \\
5 & Flower gel & $21.45 \pm 8.21^{*}$ & $50.00 \pm 8.19^{* * *}$ & $78.55 \pm 8.26^{* * *}$ \\
\hline
\end{tabular}

\section{Discussion}

The allergy to a substance is a state of hypersensitivity of the skin, immune response to antigen that appears so excessive or in appropriate, and is also manifested as erythema and edema (Elsner, 2000). The absence of these reactions reflects the non-irritant status of G. sylvestre and D. metel (Table 1 and 2). These results are different from those which showed that volatile toxic substances may have some skin toxicity (Bonnefoy, 2009). Assessment of irritation of pharmaceutical and cosmetic products with natural compounds is a significant step in the evaluation of their biocompatibility. Researchers and regulatory agencies recognize the important role of invitro and animal tests play in the biologic evaluation of cosmetic products. Based on the results obtained in this study, the two plant gels had no irritancy properties after direct application on the rat skin.

Currently, there are numerous plants used for industrial applications due to their beneficial properties. These plants (G. sylvestre and D. metel) also have significant potential for other purposes, including utilization as cosmetic ingredient. To ensure the safe use of these and other ingredients, only animal data should be submitted, such as results from Draize eye mucosal irritancy, skin irritancy and phototoxicity tests. These tests involve applying reagents/substances to rabbit/guinea pig eyes or skin. When assessing the safety of the ingredients, guidelines for use of a test material should be based on data from several skin toxicity tests. Major factors correlated with toxicity are associated with amines, nitrous compounds or detrimental substances which may be produced during plant growth, storage, preservation, processing or cooking. However, there are studies describing the antidiabetic and other biologic effects of G. sylvestre (Sugihara et al., 2000; Shanmugasundaram et al., 1981).
Normally, wound heals naturally via the homeostasis system of the body. Healing process, a natural body reaction to injury, initiates immediately after wounding and occurs in four steps. The first phase is coagulation, which controls excessive blood loss from the damaged vessels. The next stage of the healing process is inflammation and debridement of the wound followed by re-epithelization, which include, proliferation, migration and differentiation of squamous epithelial cells of the epidermis in the final stage of healing process, collagen deposition and remodelling occurs within dermis (Vogel and DeSouza, 1980). Wound contraction is the process of mobilizing healthy skin surrounding the wound to cover the denude area. This centripetal movement of wound margin is believed to be due to activity of myofibroblast. In recent years, oxidative stress has been implicated in a variety of degenerative processes and diseases; these include the acute or chronic inflammatory conditions such as wounds (Soliman et al., 2011).

In modern biomedical area, development for the management of wound healing is an expensive program for the people of developed countries, several drugs obtained from natural sources are known to increase the healing and repair processes of different types of infected wounds (Kiran and Asad, 2001).

The present study represents a comparative systematic evaluation of topical application of G. sylvestre and $D$. metel extracts. Excision wound model are often used for wound healing bioassays because they represent a true wound that could be reproducibly analyzed in a nonsubjective highly controlled manner (Mustoe et al., 1987).

In this experiment comparative evaluation of wound healing and dermal irritation study, G. sylvestre and D. metel did not show irritancy. The topical application of the gel extracts on excision wound model accelerated wound 
contraction period in rats (Tables 3 and 4). In the present study, significant difference was observed on the $12^{\text {th }}$ and $16^{\text {th }}$ days of treatment with extracts of $G$. sylvestre and $D$. metel when compared with standard and control. The efficacy of wound closure of $D$. metel leaf gel extract was better than its stem and fruit and also that of $G$. sylvestre stem, flower and leaf extracts. Only the leaf gel of the studied plants produced better activity. G. sylvestre stem and flower gel did not show much improvement in wound contraction (Table 4). Similarly, D.metel stem extract slowed the skin closure after treatment with the gel for 16 days (Table 3).

The leaf gel of G. sylvestre healed wound faster than its stem, flower and the fruit and stem gel extracts of $D$. metel. Healed wound contain comparatively less inflammatory, more collagen and angiogenesis since wound healing effect may be due to regulation of collagen expression and angiogenesis in granulation tissue improves circulation to the wound site, thus providing oxygen and nutrients for the healing processes (Suguna et al., 1996).

\section{Conclusion}

The present study evaluated whether G. sylvestre and $D$. metel extracts potentially cause skin irritation and wound healing. None of the plant extracts tested was found to irritate the skin, indicating that these plant samples may be useful in the cosmetic or cosmeceutical industry and for other applications. The two plants extracts significantly accelerated wound contraction. Further and additional evaluation on skin irritancy tests must be performed and also more parameters need to be evaluated on the wound contraction to confirm the high efficacy demonstrated in this experiment.

\section{Acknowledgment}

The authors are grateful to Mr Olupinyo Olusegun of the Department of Biochemistry laboratory for the technical assistance offered in this work.

\section{References}

[1] Fabricant, D.S. and Farnsworth, N.R. (2001). The value of plants used in traditional medicine for drug discovery. Environmental Health Perspectives. 109, 69-75.

[2] Sarker, S.D. and Hahar, L. (2004). Natural medicines: the genus Angelica. Curr. Med. Chem. II: 1479-1500.

[3] Pan, M.H., Ghai, G. and Ho, C.T. (2008). Food bioactives, apoptosis, and cancer. Mol. Nutri. Food. Res. 52: 43-52,

[4] Pan, M.H., Lai, C.S; Dushnkov, S. and Ho. C.T. (2009). Modulation of inflammatory genes by natural dietary bioactive compounds. J. Agric. Food Chem. 57: 4467-4477.

[5] Nayak, B.S., Pinto-Pereira, L.M. (2006). Catharanthus roseus flower extract has wound-healing activity in Sprague Dawley rats. BMC Complementary and Alternative
Medicines. 6: 41-47.

[6] Akinmoladun, A.C., Abukun, E.O; Afor, E., Akinrinlola B.L., Onibon, T.R., Akinboboye, O., Obuotor, E.M. and Farombi, E.O (2007). Chemical constituents and antioxidant activity of Alstonia boonei. African Journal of Biotechnology. 6: 1197-1201.

[7] Edoga, H.O., Okwu, D.E and Mbaebie, B.O. (2005). Photochemical constituents of some Nigerian medicinal plants. African Journal of Biotechnology. 4:685-688.

[8] Draize, J.H., Woodard, G., Calvery, H.O. (1994). Methods for the study of irritation and toxicity of substances applied topically to the skin and mucous membranes. J. Pharmacol. Exp. Thera. 82: 377-390.

[9] Nigam, P.K. (2009). Adverse reactions to cosmetics and methods of testing. Indian Journal - J. Dermatol Venereol Leprol. 75: 10-18.

[10] Sugihara, Y., Nojima, H., Matsuda, H., Murakami, T., Yoshikawa, M.J., Kimura, I. (2000). Antihyperglycemic effects of Gymnema sylvestre leaves in streptozotocin diabetic mice. Journal of Asian Natural Product Research. 2(4): 321-327.

[11] Shanmugasundaram, K.K., Panneerselvam, C., Sumudram, P. and Shanmugasundaram, E.R.B. (1981). Insolinotropic activity of Gymnema sylvestre, R.Br. and Indian medical herb used in controlling diabetes mellitus. Pharmacol. Res. Commun. 13(5): 475-486.

[12] Ratsch, C. (1998). The encyclopaedia of Psychoactive Plants: Ethnopharmacology and its applications.

[13] OECD (2002). OECD test guidelines 404: acute dermal irritation and corrosion: Paris, France.

[14] Yagi, A., Hine, M.A., Nsazawa, Y., Tateyama, T., Fujioka, K., Michashi, J. and Shimoruba (1998). Tetrahydroanthracene glycosides in calus tissue from Aloe barbadensis leaves. Photochemistry. 47:1267-1270.

[15] Cooper, S.P. (1987). Gums dispensing for pharmaceutical students in Corter S.L. $12^{\text {th }}$ edition C.B.S. publisher and distributor. New Delhi, Pp. 199-200.

[16] Rasheed, A.N., Afifi, F.U. and Disi, A.M. (2003). Simple evaluation of wound healing activity of crude extraction of Portualacateraceal (growing in Jordan) in: musmusanlus. JVI-1. J. Ethnopharmacol, 88: 131-136.

[17] WHO (World Health Organization). Chronicle, 39: 51.

[18] Elsuer, P. (2000). Handbook of contact dermatitis. Journal of American Academy of Dermatology, 40(4): 90-96.

[19] Bonnefoy, S. (2009). Exposition cutanee aux toxiquese volatilis et risques pour la sante. These de doctorat d'etat, universite de franche - comte, Republique de France. Pp. 118-129.

[20] Vogel, H.G. and DeSouza, N.J. (1980). Effects of terpenoids isolated from centellasiatica on granuloma tissue. Act Therapeutica. 16(4): 285-298.

[21] Soliman, Y.,Ibrahim, H., Alqasoumi, S. (2011). Antiinflammatory and wound healing activities of herbal gel containing an antioxidant Tamarix aphilla leaf extract. International Journal of Pharmacology. 7(8): 829-835. 
[22] Kiran, K. and Asad, K. (2001). Wound healing activity of Sesamumindicum L. seed and oil in rats. Indian J. Expt. Biol. 46: $7777-82$.

[23] Mustoe, T.A.,Pierce, G.F., Thomason, A.,Gramates, P., Sporn, M.B., Deuel, T.F. (1987). Accelerated healing of incision wounds in rats induced transforming growth factors. Science, 237: 1333-1336.

[24] Suguna, L., Sirakumar, P. and Chandran, K.G. (1996) Effects of Centella asiatica extract on dermal wound healing in rats. Indian J. Exp. Biol. 34: 1208-1211. 